\title{
ARTICLE OPEN Ozone balances in urban Saudi Arabia
}

\author{
M. A. K. Khalil ${ }^{1}$, C. L. Butenhoff ${ }^{1}$ and R. M. Harrison ${ }^{2}$
}

Net ozone production rates averaging $130 \mathrm{ppb} / \mathrm{h}$ lasting $3-5 \mathrm{~h}$ are calculated for five cities of urban Saudi Arabia where hourly ozone and $\mathrm{NO}_{2}$ measurements were taken for a whole year. Concentrations of ozone in the cities are not unusually high at $\sim 40$ ppb during the peak $4 \mathrm{~h}$, but are 50-60 ppb at altitude throughout the day. A mass balance of ozone reveals that the locations represented by the sites export ozone during the peak production periods before mid-day at average rates comparable to the net production, but later a substantial import of ozone is required to balance the budget. Concentrations of NO are high throughout the day ( 14 ppb) and night ( 11 ppb) and yet significant ozone concentrations remain during the night ( 18 ppb). An explanation is that large amounts of ozone are generated in the surrounding areas and aloft by ozone precursors from the cities. It is brought back during the night by transport processes and reacts with fresh emissions of NO driven by nightlife resulting in an outflow of $\mathrm{NO}_{2}$ to create the observed balances. Over the whole day, the regions represented by the sites are net sinks of ozone. We describe and support this picture of ozone balances in urban Saudi Arabia.

npj Climate and Atmospheric Science (2018)1:27; doi:10.1038/s41612-018-0034-8

\section{INTRODUCTION}

In the urban centers of the world, high levels of ozone are generated by the emissions of nitrogen oxides and hydrocarbons from automobile and other combustion sources. Health concerns due to such pollution have necessitated environmental regulations designed to keep ozone below set standards. Nitrogen dioxide itself also has direct health effects and is subjected to regulation. The air quality standards are established for criteria pollutants, which in the United States and many other countries are: $\mathrm{NO}_{2}, \mathrm{O}_{3}, \mathrm{SO}_{2}$, fine and coarse particles, $\mathrm{SO}_{2}$ and lead. ${ }^{1-3}$ In large urban areas continual measurements of these pollutants are necessary to be certain that the standards are being met. It is of scientific and practical interest to track the sources and sinks of ozone and the other criteria pollutants. ${ }^{4}$ In this paper, we delineate the balance of ozone in urban Saudi Arabia based on measurements and model calculations that form a complete set of primary variables affecting its production and loss. The results provide a deeper look at urban atmospheric chemistry in a desert environment almost devoid of biogenic emissions and with cities isolated from each other making them virtual replicates of the same urban environment.

The established understanding of the ozone balance is that it arises from the emission of mostly $\mathrm{NO}$ and some $\mathrm{NO}_{2}$ from automobiles and similar combustion sources. Sunlight breaks down $\mathrm{NO}_{2}$ making $\mathrm{NO}$ and $\mathrm{O}$ which leads to $\mathrm{O}_{3}$ formation when the $\mathrm{O}$ combines with oxygen molecules. The $\mathrm{NO}$ is converted to $\mathrm{NO}_{2}$ by combining with ozone that is present either from fresh production or before. This process creates a closed perpetual daytime cycle in which ozone is made and destroyed leaving a residual amount in the atmosphere. We see that in this cycle NO acts as a sink of ozone and $\mathrm{NO}_{2}$ as a source, hence the conversion of $\mathrm{NO}$ to $\mathrm{NO}_{2}$ is a key mechanism to make more ozone. The cycle of $\mathrm{NO}-\mathrm{NO}_{2}-\mathrm{O}_{3}$ alone chemically balances ozone at some level normally called the photo-stationary state. This balance, however, does not explain the high concentrations of ozone observed in urban areas. The main additional component is the non-methane hydrocarbons, emitted from automobiles, but may come from other sources as well, including trees and plants. These volatile organic compounds (VOCs) produce intermediate peroxy radicals that greatly increase the conversion of $\mathrm{NO}$ to $\mathrm{NO}_{2}$ thus creating an amplification of the net ozone production rate by reducing the ozone destroying $\mathrm{NO}$ and increasing the ozone producing $\mathrm{NO}_{2}{ }^{4-6}$ In real environments this chemistry is inter-twined with transport processes that reduce ozone concentrations from areas of peak production and increase them elsewhere.

From this picture, we see that the minimal ingredients to understand the ozone balance at a point in the city are the concentrations of $\mathrm{NO}, \mathrm{NO}_{2}, \mathrm{O}_{3}$, the solar radiation at the frequencies that breaks down $\mathrm{NO}_{2}$ and transport processes that move these components around. Theoretical aspects of the chemistry and mass balance of ozone in urban environments are discussed in a companion paper where a framework is created to analyze limited data sets such as the one we use here. ${ }^{7}$ The ozone balance is represented by:

$$
\begin{aligned}
& \mathrm{d}\left(\mathrm{O}_{3}\right) / \mathrm{dt}=\mathrm{PO}_{3}-\left(\mathrm{O}_{3}\right) / \tau \mathrm{O}_{3}+\mathrm{TNetO}_{3} \\
& \mathrm{PNetO}_{3}=\mathrm{J}_{\mathrm{NO} 2}\left(\mathrm{NO}_{2}\right)-\mathrm{k}(\mathrm{NO})\left(\mathrm{O}_{3}\right) \\
& \mathrm{PO}_{3}=\mathrm{J}_{\mathrm{NO} 2}\left(\mathrm{NO}_{2}\right) \\
& \tau \mathrm{O}_{3} \approx 1 / \mathrm{k}(\mathrm{NO})
\end{aligned}
$$

This is a balance of ozone in a small volume of the urban atmosphere that represents the conditions at the site where the measurements were taken. Here $\left(\mathrm{O}_{3}\right)$ represents the concentrations of ozone in ppm, $P$ is the production rate $(\mathrm{ppm} / \mathrm{h}), \tau \mathrm{O}_{3}$ is the lifetime of ozone (hours) given by Eq. (4) if destruction processes other than reactions with NO can be neglected as we will discuss

\footnotetext{
${ }^{1}$ Department of Physics, Portland State University, P.O.Box 751, Portland, OR 97207, USA and ${ }^{2}$ School of Geography, Earth and Environmental Sciences, University of Birmingham, UK and Department of Environmental Sciences, Center of Excellence in Environmental Studies, King Abdulaziz University, P.O.Box 80203, Jeddah, Saudi Arabia Correspondence: M A. K. Khalil (aslamk@pdx.edu)
}

Received: 4 December 2017 Revised: 1 March 2018 Accepted: 17 May 2018

Published online: 03 July 2018 
later. $\mathrm{TNetO}_{3}$ is the net transport of ozone in and out of the small volume represented by our site $(\mathrm{ppm} / \mathrm{h})$ so that $\mathrm{d}\left(\mathrm{O}_{3}\right) / \mathrm{dt}=$ $\mathrm{PNetO}_{3}+\mathrm{TNetO}_{3}$.

Our primary data consist of hourly measurements of $\mathrm{NO}_{2}$ and $\mathrm{O}_{3}$ during 2007 taken at all the major urban areas of Saudi Arabia, namely Riyadh (RIY), Hafouf (HAF), two sites in Damman (DPM, DIN), Yanbu (YAN) and Makkah (MAK). The data set includes two background sites at altitude $(2500-2900 \mathrm{~m})$ in Alsodah (APM, APA). Measurements were also taken at Jeddah but were unreliable and are not used in this study. No NO was reported as happens with air pollution measurements since it is not a criteria pollutant while $\mathrm{NO}_{2}$ and $\mathrm{O}_{3}$ are. A separate data set at Yanbu has hourly measurements of $\mathrm{NO}, \mathrm{NO}_{2}$ and $\mathrm{O}_{3}$ during the 6 years from 2000-2005. The two data sets, their acquisition and interpretations are in our earlier papers., ${ }^{8,9}$ Hourly meteorological data including temperature and wind speeds, for these sites and times, were obtained from WeatherSpark. ${ }^{10}$ We use these data to evaluate the chemistry and transport components of the ozone balance in urban Saudi Arabia.

\section{RESULTS}

Each of the components in Eq. 1, that is, $\mathrm{PO}_{3}, \tau \mathrm{O}_{3}$, Sink $=\left(\mathrm{O}_{3}\right) / \tau \mathrm{O}_{3}$, $\mathrm{TNetO}_{3}$ and $\mathrm{d}\left(\mathrm{O}_{3}\right) / \mathrm{dt}$, is calculated for each hour of the day. From these up to 8760 results we construct the diurnal cycle which constitutes our statement of the mass balance. The results are shown in Figs. 1 and 2.

We want to draw attention to some noteworthy points. We see that the net production rates are higher than observed in some cities of temperate industrialized countries. During the peak ozone production period, between about 9:00 a.m. and noon, average net production rates range from $60-170 \mathrm{ppb} / \mathrm{h}$. These rates are not sustained and give way to negative net transport, which means that not enough ozone is being produced in the local area to maintain the observed concentrations based on the NOx-VOC chemistry. We attribute this to transport out of the immediate region of the site. Second, we note that the diurnal pattern of the ozone cycle is similar in all the cities and distinguished from the pattern at the background sites. This similarity, we hypothesize is due to the homogeneity of the physical and cultural environments of the Saudi Arabian cities, making them virtual replicates for observations. This is because the cities are embedded in a vast desert, mostly flat and treeless, with similar climates and virtually identical cultural practices including nightlife, which puts NO and VOCs into the night air. Nonetheless, there are important differences. The peak ozone concentrations between about noon and 4:00 p.m. range from $30 \mathrm{ppb}$ to $50 \mathrm{ppb}$. Makkah is different because of the year round visits by pilgrims who are often more active at night than the day to take advantage of the cooler conditions. The similarities and differences are also affected by site selection criteria as we will discuss later. Finally, we have included calculations based on published data from independent measurements at Makkah and Jeddah to show that these data sets are consistent with the seven sites analyzed in this work. ${ }^{11,12}$ This observation supports the validity of our calculations based on a proxy NO since the results from the literature are based on actual NO measurements.

The seasonal variations of climate at the Saudi Arabian cities are small compared with more temperate industrialized countries. The production generally peaks in mid-year around June as would be expected, however, a double peak was seen at several sites with high rates during the transition months (March-April and September-October). On average the maximum production rates were $0.31 \mathrm{ppm} / \mathrm{h}$ in May, and minimums of $0.14 \mathrm{ppm} / \mathrm{h}$ during December. The sinks followed a pattern of a maximum in July of $0.64 \mathrm{ppm} / \mathrm{h}$ and a minimum in December of about $0.3 \mathrm{ppm} / \mathrm{h}$. These are averages for all the cities, and show an approximately factor of 2 variation by seasons in the sources and sinks. More interestingly the $P_{\text {Net, }}$ and therefore also $T_{\text {Net, }}$ did not change much with seasons ranging from a minimum of $0.14 \mathrm{ppm} / \mathrm{h}$ to a maximum of $0.2 \mathrm{ppm} / \mathrm{h}$ in absolute value. The seasonal variation for each city is larger than the averages, but since there is only 1 year of data, the uncertainties are also large.

The mass balance of $\mathrm{NO}$ and $\mathrm{NO}_{2}$ at night contributes to completing the picture we have presented. At night, since there are no peroxy radicals and $\mathrm{NO}$ and $\mathrm{NO}_{2}$ are not regenerated. We can therefore, apply Eq. 1 to their mass balances: $P_{\mathrm{Net}} \mathrm{NO} \approx-$ $T_{\mathrm{Net}} \mathrm{NO}, P_{\mathrm{Net}} \mathrm{NO}_{2} \approx-T_{\mathrm{Net}} \mathrm{NO}_{2}, P_{\mathrm{Net}} \mathrm{NO}=-\mathrm{k}_{4}\left(\mathrm{O}_{3}\right)(\mathrm{NO})$, and $P_{\mathrm{Net}} \mathrm{NO}_{2}=$ $+\mathrm{k}_{4}\left(\mathrm{O}_{3}\right)(\mathrm{NO})^{7}{ }^{7}$ The results show that a net influx of $\mathrm{NO}$ is required to explain the observed concentrations along with an influx of ozone as shown in Fig. 1. As these react, they create a imbalance of $\mathrm{NO}_{2}$ resulting in a net outflow. The calculations show that between 20:00 and 05:00 $\mathrm{h}$ an average of 230 (range 160-350) $\mathrm{ppb} / \mathrm{h}$ of $\mathrm{NO}$ influx and a similar outflow of $\mathrm{NO}_{2}$ are needed to explain the observed concentrations of these gases. The high end is represented by Makkah, while the rest of the sites are closer to the average. This result creates a consistent picture of the ozone balance in urban Saudi Arabia including the flows of $\mathrm{NO}$ and $\mathrm{NO}_{2}$ at night that result in the net sink of ozone within the core of the cities.

\section{DISCUSSION}

Local lifetimes

The lifetime of ozone is calculated by Eq. 4 and the lifetimes of NO and $\mathrm{NO}_{2}$ can be calculated similarly within the assumptions of the main chemical cycles adopted here. ${ }^{7}$ For NO, the reaction with ozone provides a rapid sink and $\tau \mathrm{NO}=1 / \mathrm{k}\left(\mathrm{O}_{3}\right)$. The actual daytime lifetime is shorter than this because of the reaction of NO with peroxy radicals, which we cannot estimate with the data in hand. For $\mathrm{NO}_{2}$ the main sink is the photolysis $\tau \mathrm{NO}_{2}=1 / \mathrm{J}$ and at night we take it to be the reaction with ozone. There may be other loss processes for $\mathrm{NO}_{2}$, but these are likely to be smaller. The resulting local lifetimes for $\mathrm{NO}, \mathrm{NO}_{2}$ and $\mathrm{O}_{3}$ are shown in Fig. 3 .

In Eq. 1, which is the anchor of our analysis, we have assumed that the chemistry of ozone balance processes is completely described by the interactions of $\mathrm{J}, \mathrm{NO}, \mathrm{NO}_{2}$, and $\mathrm{O}_{3}$ with the intervention of VOCs that transfer $\mathrm{NO}$ to $\mathrm{NO}_{2}$. Within this framework there is still room for significant impacts of additional sources and sinks of all these species. Since we are dealing with only the ozone balance here, we investigated the effect of other known sinks on its mass balance. There are no significant known sources other than the $\mathrm{O}+\mathrm{O}_{2}->\mathrm{O}_{3}$ that is already included. If there are additional sinks, these must be added to the right hand side of Eq. 1 and may be written as - $\left(\mathrm{O}_{3}\right) / \tau$ Other where $1 / \tau$ Other is the sum of the inverse lifetimes due to the other processes. If this term is important, then it must be added to the loss-term in our mass balance. It would decrease the net transport needed to balance the observations during the day and increase the need for transported ozone during the night.

Under low NO conditions these other sinks of ozone may be important, however, for the conditions in the urban areas, particularly in Saudi Arabia, the NO concentrations dominate the sink term in Eq. 1. We looked at five additional sinks, namely, $\mathrm{OH}$, $\mathrm{NO}_{2}$, VOCs, dry deposition, and sunlight. Our estimates are biased towards making the lifetimes due to these processes shorter than the actual circumstances are likely to be so as to estimate the upper limit of ozone destruction by the other sinks.

For $\mathrm{OH}$ we assumed $10^{7}$ molecules/ $\mathrm{cm}^{3}$ average during the day that follow the diurnal cycle of ozone and no $\mathrm{OH}$ at night. ${ }^{13-15}$ For the $\mathrm{VOC}-\mathrm{O}_{3}$ reactions we used a rate constant with propylene $\left(\mathrm{C}_{3} \mathrm{H}_{6}\right)$, which reacts with ozone more rapidly than most of the hydrocarbons in the urban mix. This is an extreme assumption in which we take the propylene-equivalent VOC to be the measured VOC concentration. The VOC concentrations were taken from 

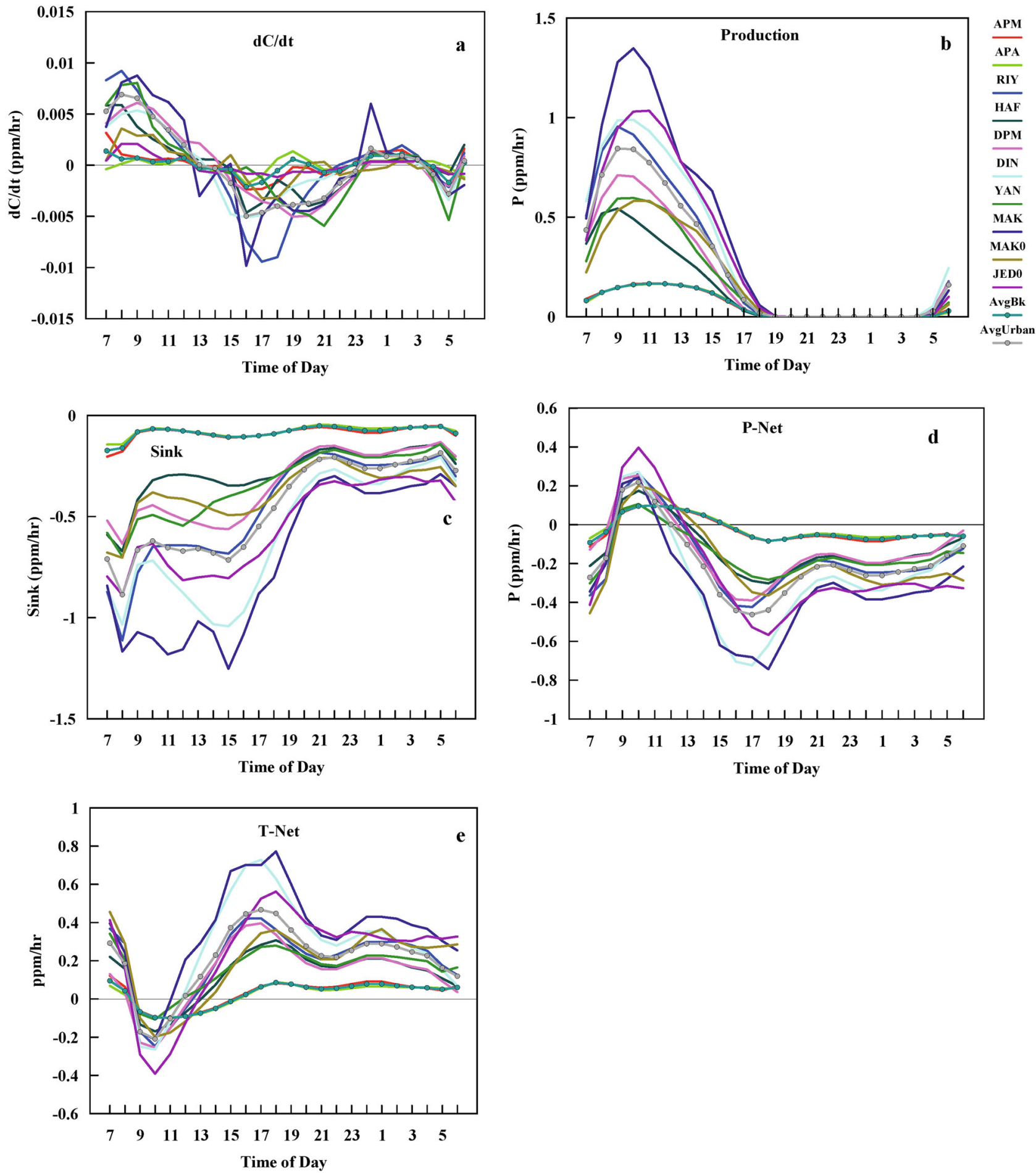

Fig. 1 The ozone mass balance components: a dC/dt, b $\mathrm{PO}_{3}, \mathbf{c}$ Sink, $\mathbf{d} \mathrm{PNetO}_{3}$, and e $\mathrm{TNetO}_{3}$ in urban Saudi Arabia. The calculations of these components for two data sets from the published literature are shown as MAKO and JEDO supporting the results of this work

measurements at Yanbu reported previously. ${ }^{9}$ The photodissociation sink was calculated as $\mathrm{JO}_{3} \approx 0.0028 \times \mathrm{J}_{\mathrm{NO} 2}$ (ref. ${ }^{5}$ ). The dry deposition sink was calculated using the GEOS-Chem model, ${ }^{16}$ which provided hourly effective mixing height $\mathrm{H}(\mathrm{km})$ and a deposition velocity $v \operatorname{Dep}(\mathrm{km} / \mathrm{h})$ from which the lifetime was calculated as $\tau \operatorname{Dep}(h)=H / v D e p$. The deposition rates are similar at all the sites in our study and were averaged. The results of these calculations are shown in Fig. 4 where we have also included the reaction of $\mathrm{O}_{3}$ with $\mathrm{NO}$ for comparison. The combined effect of the other sinks is $<5 \%$ for all hours of the day at the urban sites but for the background sites at Alsodah, the effect is between 10 and $30 \%$ depending on the hour of the day.

Effect of transport processes

We see from the mass balance calculations that ozone concentrations are constantly and significantly affected by transport processes. During times of peak ozone production, it is 

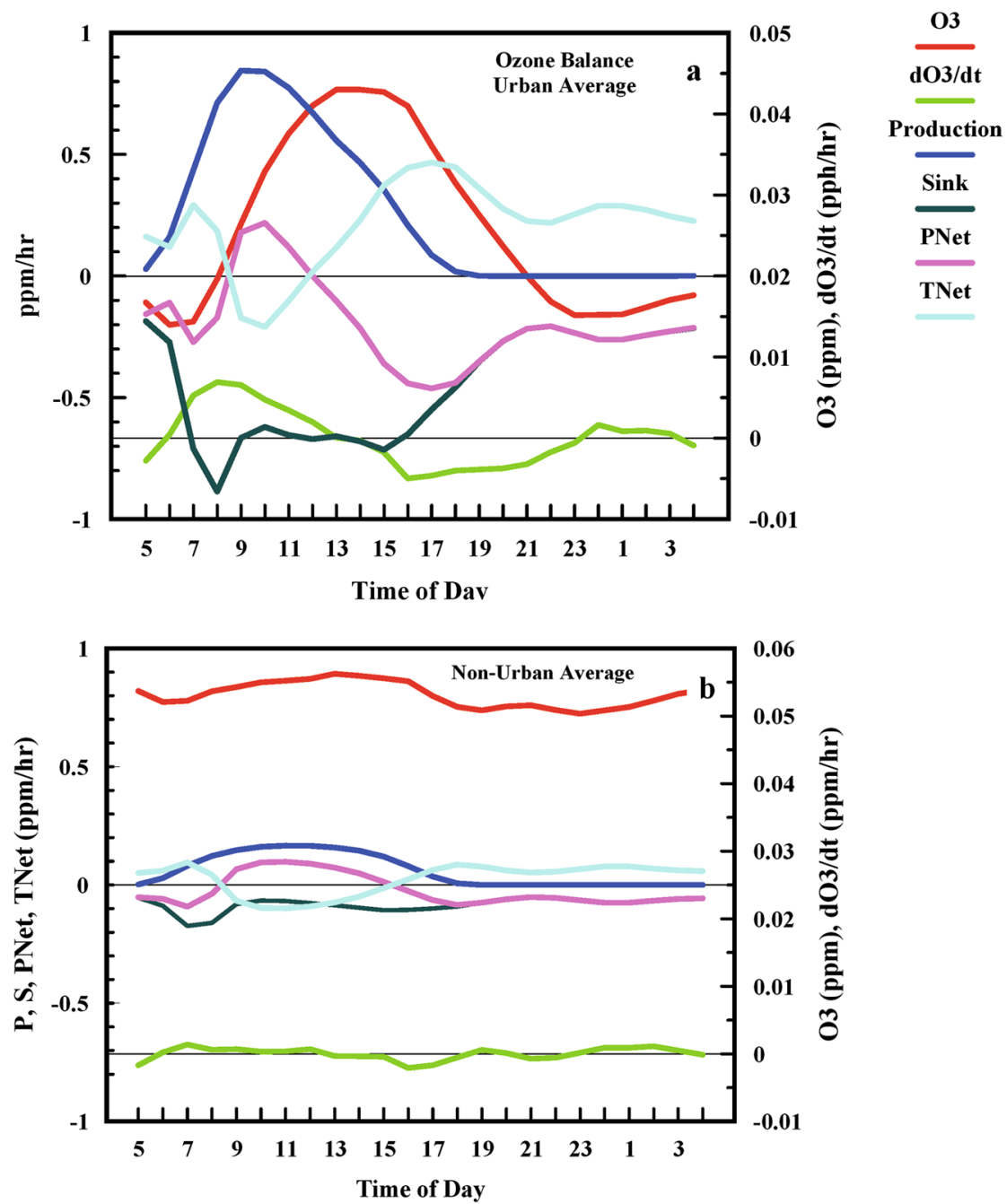

Fig. 2 Contrast between urban and non-urban ozone average mass balance components in Saudi Arabia. Estimates are shown on the same scales

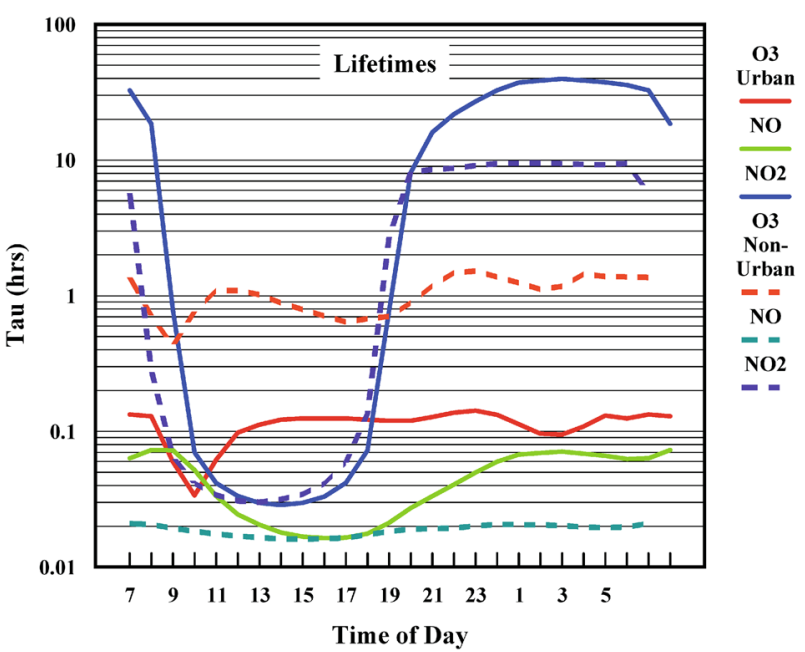

Fig. 3 The local lifetimes of $\mathrm{O}_{3}, \mathrm{NO}, \mathrm{NO}_{2}$ at urban and non-urban sites in Saudi Arabia based on core ozone chemistry. The actual lifetime of NO during the day is likely to be lower due to the peroxy radical reactions

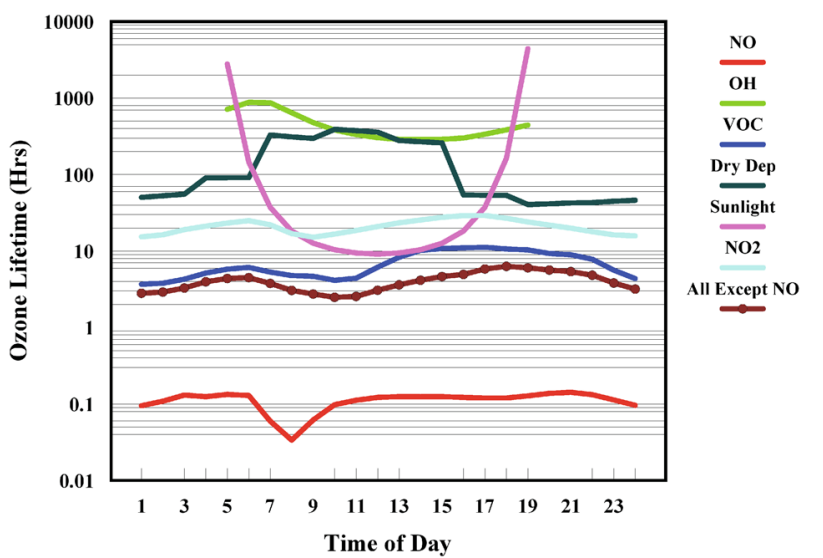

Fig. 4 Comparison of urban ozone sinks. The lifetime of ozone is dominated by its reaction with NO, especially at urban sites with high levels of $\mathrm{NO}$ 


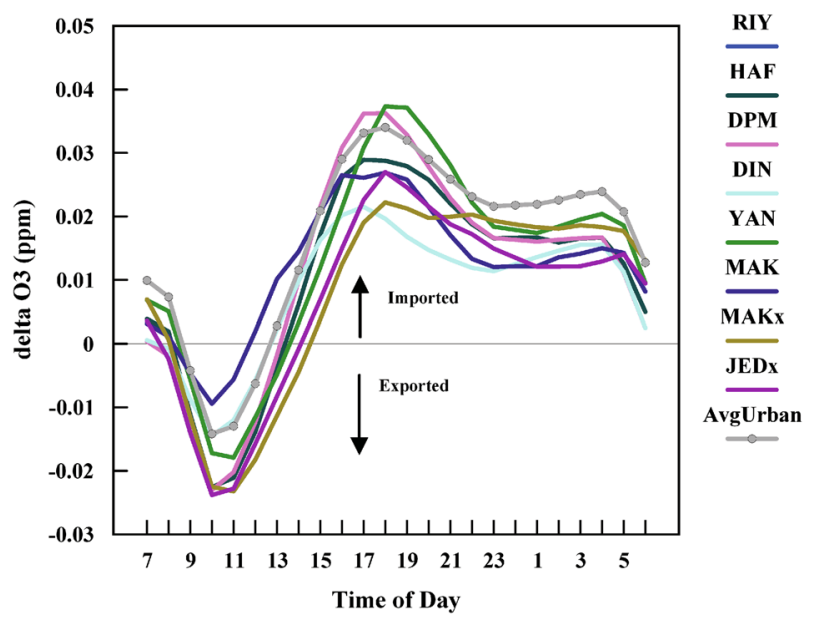

Fig. 5 The contribution of transport processes to the observed ozone at the urban and background sites. When it is positive, ozone is being imported to the site of observations and when negative it is being exported

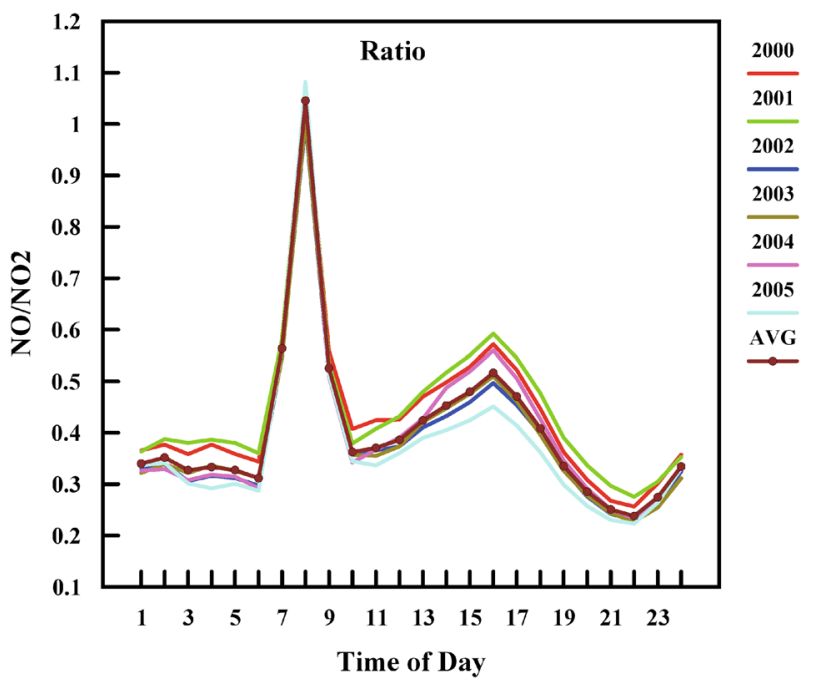

Fig. 6 The diurnal cycle of $\mathrm{NO} / \mathrm{NO}_{2}$ ratio calculated from measurements taken at Yanbu. Data were not used from the year mentioned in the caption making it suitable for the calculation of proxy NO for that year
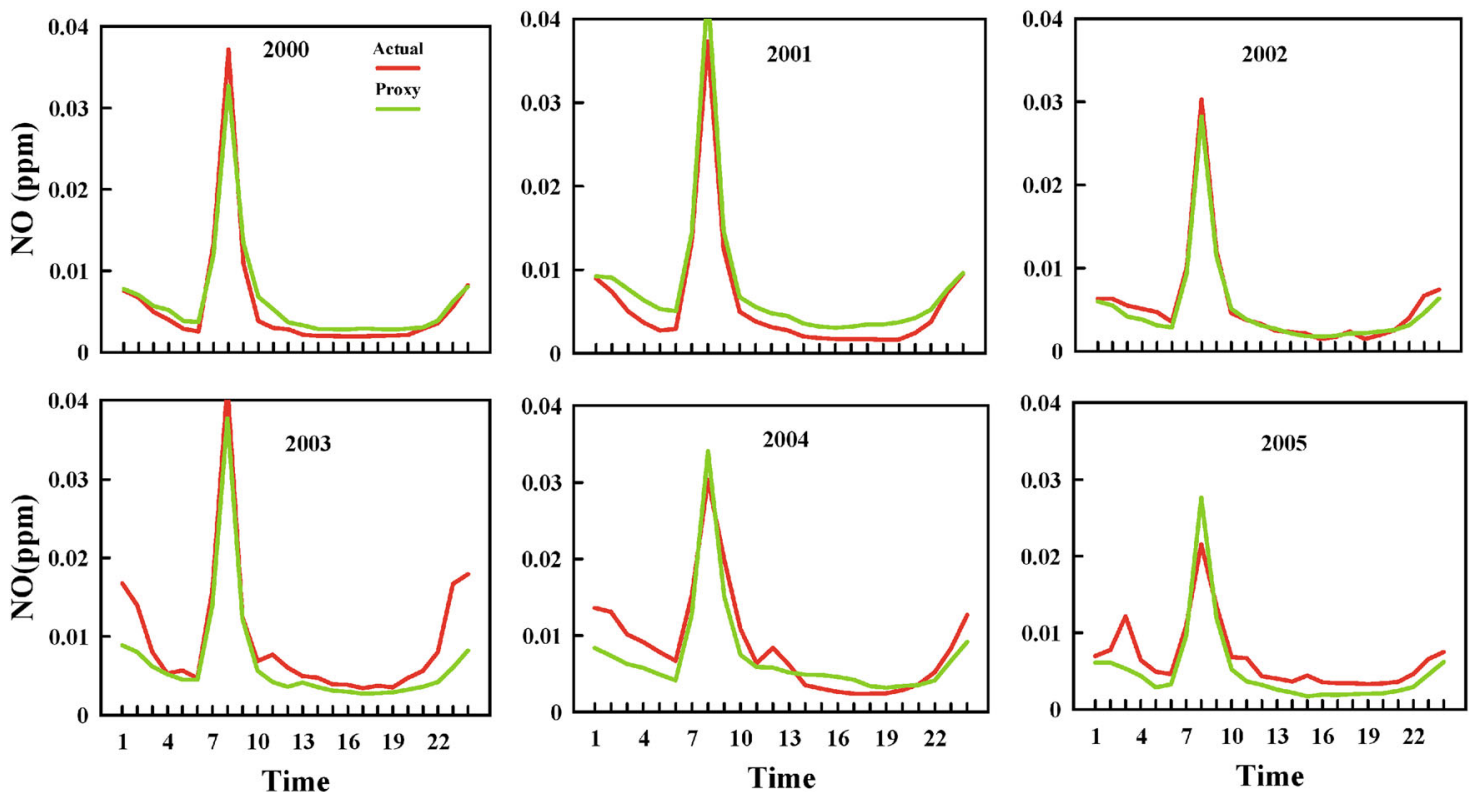

Fig. 7 The measured and proxy NO representing the average diurnal cycle at Yanbu. The ratio was weighted with annual average ozone as discussed in the text

transported out of the region from our sites and for the rest of the time, particularly at night, ozone is imported from the outside.

We note that $\mathrm{d}\left(\mathrm{O}_{3}\right) / \mathrm{dt}$ is at most $4 \%$ of the sink term $\left(\mathrm{O}_{3}\right) / \tau \mathrm{O}_{3}$ in absolute value, therefore, pseudo-steady-state assumption can be made. ${ }^{4-7}$ We can evaluate, what the ozone concentration would be if was to be in balance with the measured $\mathrm{NO}$ and $\mathrm{NO}_{2}$ and ignoring transport processes from Eq. (1):

$$
\left(\mathrm{O}_{3}\right)_{\mathrm{HPSS}}=\mathrm{J}_{\mathrm{NO} 2}\left(\mathrm{NO}_{2}\right) / \mathrm{k}(\mathrm{NO})
$$

If we then say that $\left(\mathrm{O}_{3}\right)$ meas $=\left(\mathrm{O}_{3}\right)_{\mathrm{HPSS}}+\delta\left(\mathrm{O}_{3}\right)$ where the latter term is the effect of transport and put this into Eq. 1 we get:

$\delta\left(\mathrm{O}_{3}\right)=T_{\mathrm{Net}} \mathrm{O}_{3} \tau \mathrm{O}_{3}$

It says that the net transport acts as a "source" leading to a steady-state contribution of $\delta\left(\mathrm{O}_{3}\right) . T_{\mathrm{Net}} \mathrm{O}_{3}$ can be a "negative source" unlike a normal one. In Fig. 5 we show our estimate of the contribution of transport to ozone at the various sites.
The main points of these calculations are that transport processes reduce the ozone concentrations during peak production hours of 09:00-13:00 $\mathrm{h}$ by between 5 and $25 \mathrm{ppb}$, depending on the site and about $16 \mathrm{ppb}$ on average or by about $30 \%$. During the night, all the ozone we see is imported and is about $18 \mathrm{ppb}$ on average. This is because there is so much NO present that if it were not for transported ozone, the concentrations would go to zero very quickly after sunset since it can no longer be produced and its initial lifetime is $<10 \mathrm{~min}$.

Origins of transported ozone

With the importance of transported ozone demonstrated we discuss the possible origins of transported ozone. Ozone pools generally exist aloft. ${ }^{16,17}$ We consider first the significant difference of $\mathrm{O}_{3}, \mathrm{NO}$, and $\mathrm{NO}_{2}$ lifetimes inside the urban area compared with outside. In the desert environment, NO is emitted inside the cities 


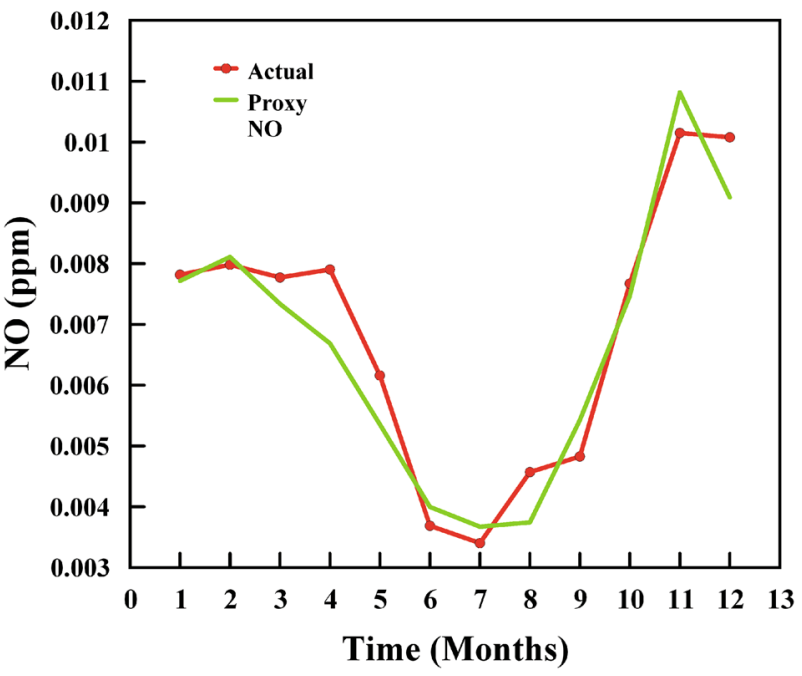

Fig. 8 The pattern of seasonal variations of measured and proxy NO at Yanbu
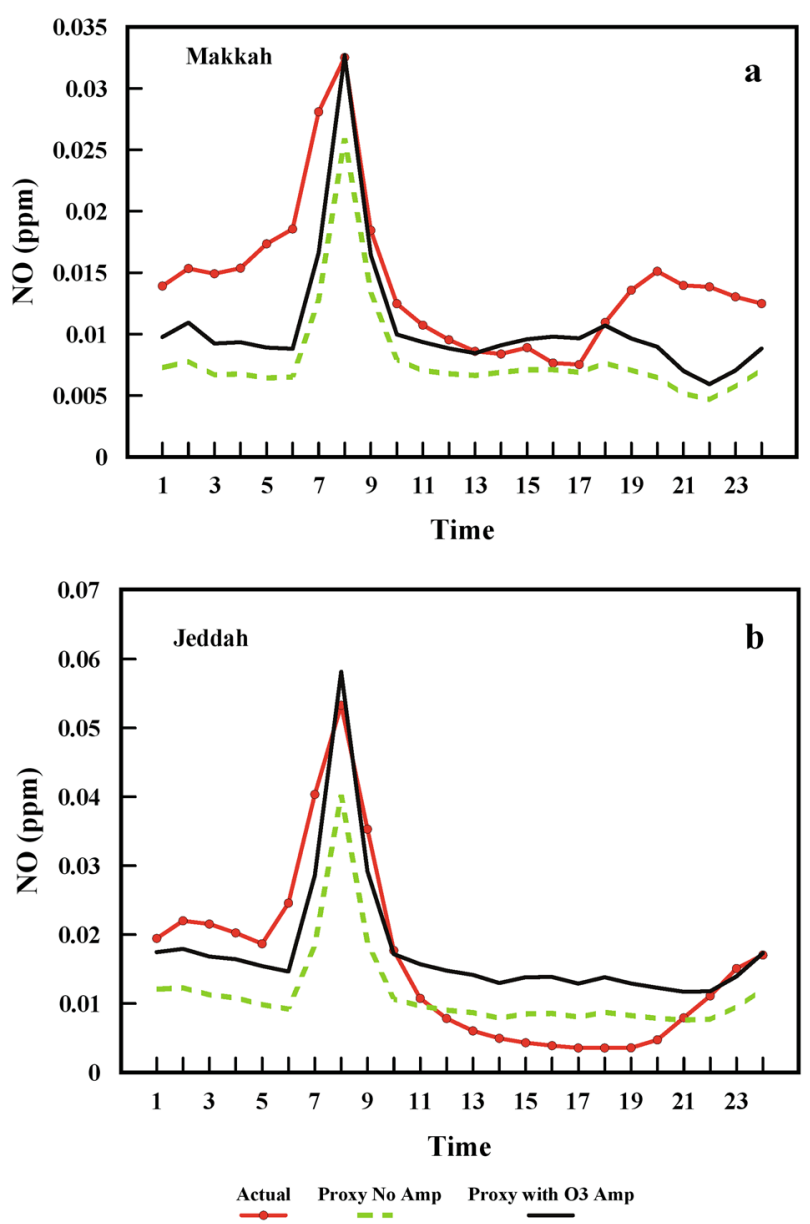

Fig. 9 The proxy NO method is tested by applying it to other sites in Saudi Arabia where ozone and precursor observations were taken and published in the literature. Calculations show a marked improvement when the ratio is weighted with the annual average ozone with little or no emissions outside. The directly emitted NO does not make it too far due to its short lifetime and it's regeneration during the transit would favor partitioning into more $\mathrm{NO}_{2}$ and less NO as ozone concentration builds. Considering the situation outside the cities, and aloft, we expect low concentrations of NO and sufficient $\mathrm{NO}_{2}$ to result in high levels of ozone. Such a pattern is indeed observed at the Alsodah background sites that are at $2.5-3.0 \mathrm{~km}$. Here $\mathrm{NO}$ is ten times lower than the cities, $\mathrm{O}_{3}$ is higher than in any of the cities day and night and $\mathrm{NO}_{2}$ is five times lower. At sites closer to the city, these balances may be even more favorable to high ozone conditions. This large pool outside can supply ozone to the cities later in the daytime when net production in the cities drops and the gradients shift to pointing towards the cities. Certainly at night, the cities with their continued emissions of NO can become net sink areas for ozone that comes from aloft driven by transport processes including the lowering of the mixing height.

Our data are from one site in each city, so it is not possible to evaluate nearby ozone concentrations. Supportive evidence for high ozone concentrations just outside Saudi cities comes from two published studies where simultaneous measurements were taken at many sites in and near Jeddah. ${ }^{18,19}$ The studies choose different locations and were a year apart. In the Porter study, ${ }^{19}$ only daily concentrations were available, however, the results showed that the average concentration of ozone at the five urban sites was about $15 \mathrm{ppb}$, but at the two remote sites it was $40 \mathrm{ppb}$ ! NOx was higher at the urban sites compared with remote sites, a result similar to our data from the various cities and the two Alsodah background sites. In the Hassan study, ${ }_{1}^{18}$ there were six sites, and hourly measurements were taken only during the daytime. Ozone concentrations at the urban sites were between 20-30 ppb and were $40-60 \mathrm{ppb}$ at the two remote sites, reaching peaks of $60-70 \mathrm{ppb}$. The lowest concentration of ozone was seen at the city center. These results confirm that high levels of ozone are present outside the cities and are, therefore, a potential source to urban areas when net production inside the cities declines later in the day and is negative at night.

Although nightlife explains the ozone patterns, there are no studies that quantify night-time traffic that we are aware of, however, there is anecdotal evidence on the internet. ${ }^{20}$ Further support for this cause comes from the data which show not only large amounts of $\mathrm{NO}_{2}$ in the night atmosphere as reported here, but also night-time peaks of $\mathrm{NO}$ and NMHCs at Yanbu ${ }^{10}$ and peaks in $\mathrm{CO}$ at the other urban sites. ${ }^{9}$ These are signatures of traffic emissions. While the lifetimes of all these gases are much higher at night than the daytime, this would lead to stable concentrations and any increases that are observed would still have to come from more emissions or some complex meteorological mixing phenomenon, which is possible but unlikely. During Ramadan, it is known that there is more night-time activity in all the cities and in Makkah, there is year round night-time activity since Omrah pilgrims prefer the cooler night conditions to carry out the required rituals. Quantifying the night-time traffic emissions in urban Saudi Arabia remains an important scientific issue to explain the night-time ozone balance.

While the diurnal patterns of $\mathrm{NOx}$ and $\mathrm{O}_{3}$ are similar at all the sites, there are considerable differences in the magnitudes. We consider the key components-Measured $\mathrm{O}_{3}$, NOx (NOx= measured $\mathrm{NO}_{2}+$ proxy $\mathrm{NO}$ ), calculated $\mathrm{PNetO}_{3}$ and $\mathrm{TNetO}_{3}$. For the peak production period from 9-12 the average ozone is $38 \mathrm{ppb}$ with a range from $28-45 \mathrm{ppb}$; for NOx the average is $38 \mathrm{ppb}(19-64 \mathrm{ppb}) ; \mathrm{PNetO}_{3}$ average is $130 \mathrm{ppb} / \mathrm{h}(60-170 \mathrm{ppb} / \mathrm{h})$ and the $\mathrm{TNetO}_{3}$ averages are about the same as minus $\mathrm{PNetO}_{3}$ because the concentrations are in an approximate pseudo-steadystate. This amounts to a variability in ozone of about a factor of 1.7 and in the other variables of about 3 . During the night period (22:00-04:00 h) without sunlight and with diminished influence from the day's activity, these key ozone balance variables are 

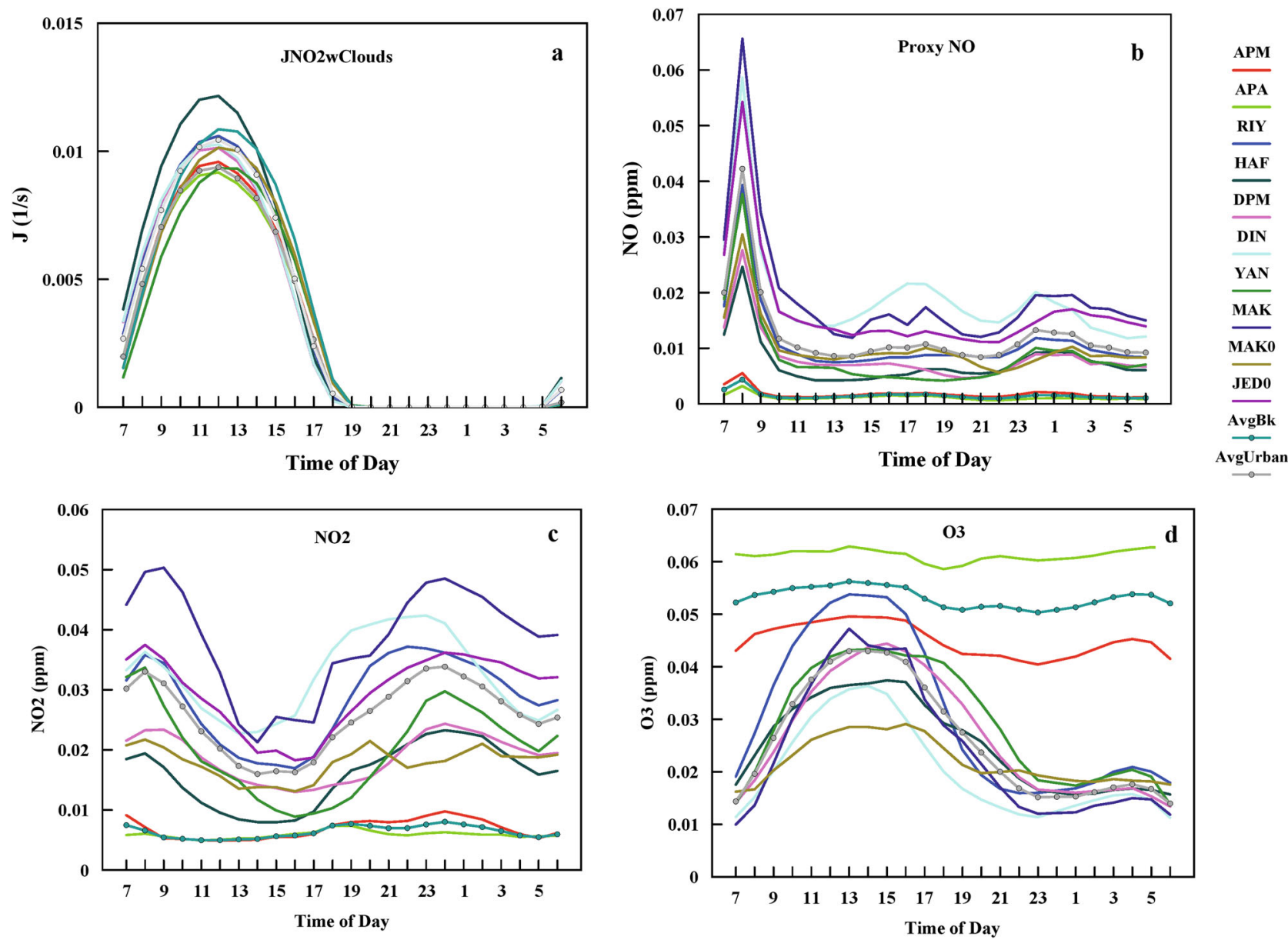

Fig. 10 Diurnal cycles of measured and calculated ingredients of the ozone mass balance at urban sites in Saudi Arabia. a calculated $\mathrm{J}_{\mathrm{NO}}, \mathbf{b}$ proxy $\mathrm{NO}, \mathbf{c}$ measured $\mathrm{NO}_{2}$, and $\mathbf{d} \mathrm{O}_{3}$

much more alike among cities. Ozone is about $16 \mathrm{ppb}$ (13-19 ppb - a small variation among the cities); NOx is $40 \mathrm{ppb}(30-60 \mathrm{ppb})$, and the $T_{\mathrm{Net}} \mathrm{O}_{3}$ is about $260 \mathrm{ppb} / \mathrm{h}(180-390 \mathrm{ppb} / \mathrm{h})$ but positive, indicating inflows. The mass balance shows that the areas around the sites are a net sink of ozone when averaged over the whole day $(24 \mathrm{~h})$, however, the ozone they destroy at night is likely produced by daytime precursors from the same cities.

Perhaps the remarkable aspect is the high level of NOx at night, which is also apparent in the diurnal cycle in Fig. 10 in the next section. In looking at the disparities of the ozone balance variables between cities Makkah stands out as having the highest levels of NOx, $T_{\text {Net}}$, production and sink, both day and night, of any of the cities. It does not have the highest ozone, however, possibly because there is so much NOx that the cycle is saturated. The daytime ozone at Makkah is about the same as Hafouf, which is the smallest city in our data set and has the lowest NOx, ozone production and sinks day or night.

Since the net transport processes are necessary to balance ozone in all the cities, we want to add to the discussion here. We can separate transport into two types-local and rural. Because a single site represents a point measurement, the calculated transport influence at the site is dominated by local gradients and variations of the concentrations of $\mathrm{O}_{3}$ and $\mathrm{NO}_{2}$. As such it does not represent the larger scale exchanges between the polluted urban air and the surrounding rural or regional atmosphere. To quantitatively understand the exchanges between the urban environment and the surroundings, measurements and model calculations are needed to map the spatial distribution of the chemical processes and concentrations. This was not possible with the data we had in hand.

In any city there are likely to be one or more hot spots of ozone and its precursors where the concentrations are highest, and other locations where they are low. If a site was located in a hot spot for ozone, the net transport should be negative throughout the day or as long as the highest concentrations are maintained at the location relative to the air within a short distance. If the site is located in one of the low ozone regions, a positive net ozone transport will be seen during the day. If a site is mostly importing ozone, it will not represent a location of high ozone concentrations that may violate standards. Other locations will vary between these extreme cases and this is what we see at the sites selected for the urban Saudi Arabia measurements. By the same reasoning, the net production calculated at any one site does not represent the rates over the entire city either in magnitude or diurnal pattern because precursors such as $\mathrm{NO}_{2}$ and VOCs are being brought in from local areas of varying traffic and other activities within the city.

\section{METHODS}

Since NO is a crucial ingredient for the calculation of net ozone production and its mass balance, we developed a proxy based on the available $\mathrm{NO}_{2}$ measurements. We used the ratio of $\mathrm{NO} / \mathrm{NO}_{2}$ calculated from the Yanbu data set, where we have NO measurements and weighted it by the annual ozone concentrations to estimate a hourly proxy NO at each site. $\mathrm{J}_{\mathrm{NO} 2}$ was not measured in either of the experiments and was calculated using standard models (TUV and Geos-Chem). ${ }^{21,22}$ No measurements of peroxy radicals or the VOCs were taken. While this would have added important 

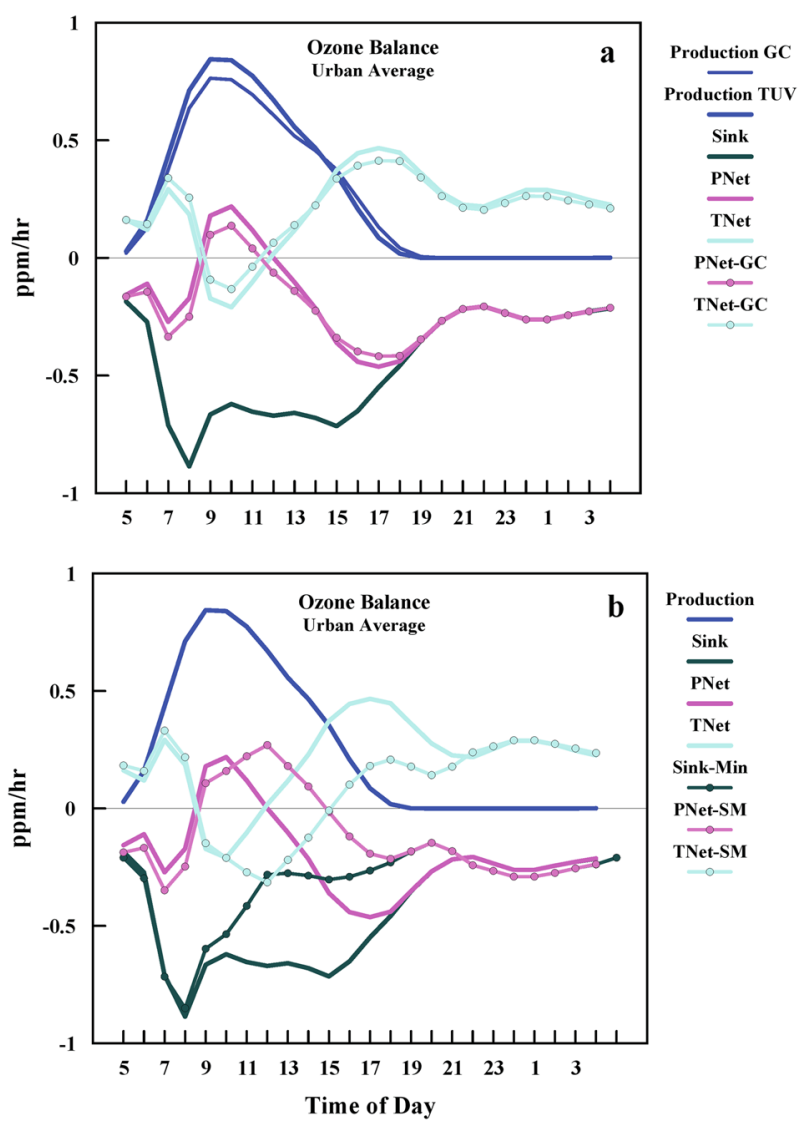

Fig. 11 Evaluation of uncertainties and sensitivities in ozone balance calculations for urban Saudi Arabia. a The effect of reducing the NO concentrations by a factor of two during the PM as suggested by comparison of the proxy NO with observations from the literature. $\mathbf{b}$ The effect of two different models for calculating $\mathrm{J}_{\mathrm{NO} 2}$

information, we note from Eq. 1 that a mass balance of ozone can still be carried out knowing the $\mathrm{NO}$ and $\mathrm{NO}_{2}$ concentrations because the effect of these intermediaries is included in the measured concentrations. With these additions, we can complete the ingredients required to evaluate the components in Eq. 1 . We can directly calculate $\mathrm{d}\left(\mathrm{O}_{3}\right) / \mathrm{dt}$ and $\mathrm{PNetO}_{3}$ and use the results to calculate $\mathrm{TNetO}_{3}$ required to balance the equation. This plan produces the results that are most tightly constrained by observations.

\section{Proxy NO}

A weighted ratio of $\mathrm{NO}$ and $\mathrm{NO}_{2}$ for each hour of the day during the year was calculated using the Yanbu data where both were measured for 6 years. From this ratio, we can calculate the $\mathrm{NO}$ at each of the major cities of Saudi Arabia using the measured $\mathrm{NO}_{2}$. The method is validated on the data from Yanbu for each year by using only the measurements from the other years, and it is also verified on independent published measurements at Makkah and Jeddah. The proxy NO makes it possible to obtain net ozone production rates $\mathrm{PNetO}_{3}$ and an ozone balance at each location according to Eq. 1.

The ratio is calculated thus:

$(\bar{C})_{i}=\frac{1}{N} \sum_{j=1}^{N}(C)_{i j}$

$R_{i 0}=(\overline{\mathrm{NO}})_{i} /\left(\overline{\mathrm{NO}}_{2}\right)_{i}$

(C) is the concentration of a gas which for our case will be $\mathrm{NO}$ or $\mathrm{NO}_{2}$. The $j$ indexes the years going from 1 to 6 and $i$ indexes the hours in the year going from 1 to 8760 . The ratio $R_{i} 0$ is, therefore, the average ratio for a given hour of the day where the average is taken over the 6 years of data. Although the ratio is calculated for each hour of a year, its purpose is to produce accurate diurnal cycles and monthly averages. The diurnal cycle is of the most interest for our data sets since it represents a characteristic index of air pollution at the sites and it is the primary measure of whether standards are met or not. Seasonal changes although of interest, are not large for our circumstances.

While the $R_{i 0}$ calculated in Eq. (8) represents the pattern at one location, applying it to other locations is better served if some of the differences affecting ozone and NOx are included. From ozone chemical theory, the ratio of $\mathrm{NO} / \mathrm{NO}_{2}$ is generally inversely related to the amount of ozone present, however, the exact relationship is complicated by chemical and transport process. We use the annual average ozone to take this into account. So to calculate the proxy NO at a site for each hour of the year, we use the following equation:

$\operatorname{proxy}(\mathrm{NO})_{i}$ Site $=R_{i 0}($ Base Site $) \cdot \frac{\overline{\left(\mathrm{O}_{3}\right)} \text { Base Site }}{\overline{\left(\mathrm{O}_{3}\right)} \text { Site }} \cdot\left(\mathrm{NO}_{2}\right)_{i}$ Site

We calculated six such ratios from the 6 years of data at Yanbu. Each ratio included all the years except one, creating a ratio applicable to the missing year (Fig. 6). The proxy can be compared with the actual measured NO for the year missing from the ratio (Figs. 7 and 8). This constitutes the first test of the performance of the ratio, which we expect to do better than when we apply the ratio to other sites.

We see from these figures that the proxy NO performs very well when applied to the location from which the underlying ratio was calculated during different years. The second test is to extend it to other sites where we expect similar conditions and see if it can predict NO adequately. For this test, we used published measurements taken at Makkah (2002-2003) and Jeddah (2013-2014) representing urban environments similar to Yanbu (where the base ratio is calculated). ${ }^{11,12}$ Data in these papers are given as the hourly diurnal cycle for each season. For our calculations this cycle was repeated for each day of the months it represents generating hourly values of $\mathrm{NO}, \mathrm{NO}_{2}$, and $\mathrm{O}_{3}$ for the whole year over which measurements were taken. Then, these data sets were subjected to the same analysis as the hourly Yanbu data shown in the previous figures using hourly ratios of $\mathrm{NO} / \mathrm{NO}_{2}$ from Yanbu. The results are shown in Fig. 9 both with and without the annual average ozone weighting.

We can quantify the uncertainties generated by the proxy NO by defining the absolute and percent differences between the proxy and actual measurements: $\delta(\mathrm{NO})=\mid(\mathrm{NO})$ measured - NO (proxy) $\mid$ and $\delta(\mathrm{NO}) /$ (NO)measured $\times 100 \%$ for each averaged value, diurnal or monthly.

The salient points are that the proxy reproduces NO peaks, between 7:00 a.m. $-9: 00$ a.m., to better than $20 \%$ both at new Yanbu (6\%-17\%) and other independent sites where it was applied-Makkah and Jeddah (18\%-19\%). New Yanbu refers to the data from this city that is in the many sites set we are analyzing here as opposed to the independent data set at Yanbu from which the ratio was calculated. For night-time NO (1-6 a.m., 8-12 p.m.) is good to within about $30 \%$. Finally for the daytime after the peak (10:00 a. m.-7:00 p.m.), it does very well for Makkah (within 14\%) but does poorly for Jeddah (170\%) and for new Yanbu it is within about $40 \%$. A study by Hassan et al. (2013) reported the annual average of $\mathrm{NO}, \mathrm{NO}_{2}$, and $\mathrm{O}_{3}$ for several sites at Jeddah during the daylight hours. Their results for urban sites show about $17 \mathrm{ppb}$ of NO between 11:00 a.m. and 8:00 p.m. while our proxy predicts $14 \mathrm{ppb}$ for this period. This agreement is supportive of the proxy NO estimates for Jeddah for this time of day. It is noteworthy that using percent deviations amplifies the discrepancies when the concentrations are low. The lower the NO ambient concentrations are, the more difficult it is to measure them, and similarly difficult to get a good proxy estimate. This causes some level of uncertainty that is not related to the proxy which we cannot assess. Depending on how the NO data are used the impact of such uncertainties, whether from inaccuracy of the measurements or the failure of the proxy may or may not matter when the concentrations are very low as is the case here. Proxy NO results are shown in Fig. 10b

\section{$\mathrm{NO}_{2}$ photolysis rates}

We calculated $\mathrm{NO}_{2}$ photolysis coefficients at each site using the Tropospheric Ultraviolet and Radiation (TUV) model. ${ }^{21,22}$ Hourly coefficients were calculated on a daily basis for a full year using contributions from both direct and diffuse radiation. Annually averaged surface albedos were specified at each site using the MODIS MCD43 albedo product for January and July. ${ }^{23}$ For efficiency we used the two-stream approximation of radiative transfer, which contributes a $1-3 \%$ bias in photolysis coefficients relative to the more accurate but computationally expensive four-stream approximation based on a sensitivity test we ran with TUV. Cloud effects 
were included in the calculations as represented in the model. Results are shown in Fig. 10.

\section{Uncertainties and sensitivities}

There are two areas where we have no direct measurements requiring a model calculations-the $J_{\mathrm{NO} 2}$ and proxy $\mathrm{NO}$. We can evaluate how potential inaccuracies in these may affect our conclusions. For the proxy NO validation our comparison with the independently published results showed an overestimate by about a factor of 2 in the PM times at Jeddah and a close agreement at Makkah (Fig. 4, and refs ${ }^{11,12}$ ). We tested the potential effect by reducing the concentrations of $\mathrm{NO}$ at all sites for this time by a factor of 2 and re-evaluating the mass balance. The results were averaged for all the urban areas since the consequences are about the same (Fig. 11a). The lower NO does not change the peak of the net ozone production, but extends it in the positive range for another $2-3 \mathrm{~h}$. The average net production for the whole day is increased from $-0.22 \mathrm{ppm} / \mathrm{h}$ to $-0.12 \mathrm{ppm} / \mathrm{h}$ thus reducing the needed net import of ozone by the same amount. The result remains that there is a net loss of ozone at the observation sites during the $24 \mathrm{~h}$.

The $\mathrm{J}_{\mathrm{NO} 2}$ was re-calculated using the GEOS-Chem model, which resulted in a somewhat lower peak than the TUV model by about $15 \%$ which translated into an average of about $12 \%$ reduction in the peak ozone production rate. The production based on this $J_{\mathrm{NO} 2}$ was propagated in the calculations of the mass balance with results that are only slightly different as shown in Fig. 11b. In both calculations the clouds were included as prescribed in the models. Actual cloud observations reported in the WeatherSpark data were also used to evaluate the effects. None of these turned out to be large, in part because there are not many clouds over Saudi Arabia as most satellite pictures would attest. At other locations, the cloud effect may be much more important and may depend on the model used.

Data availability

The data used in this research are available as a Microsoft Excel file in the Supplementary Material.

\section{ACKNOWLEDGEMENTS}

This work was supported by the resources of Andarz Co., Portland, Oregon. Initial support for research in this area was provided by King Abdulaziz University (KAU) under grant no. (4-10-1432/HiCi). The Presidency of Meteorology and Environment (PME) in Saudi Arabia provided the observational data sets in a collaboration with the Center of Excellence for Climate Change Research of KAU. Additional support was provided by the Center for Climate and Aerosol Research and the Institute of Sustainable Solutions at Portland State University.

\section{AUTHOR CONTRIBUTIONS}

C.B. contributed to model calculations and provided support to integrate his previous work on this project and the data set. R.H. provided vital information, insights, discussions, and results that improved the proxy calculations and the mass balances. His efforts also led to a re-evaluation of ozone balances in the published literature. A. $\mathrm{K}$. initiated and conducted the research and wrote the paper. The motivation of authors was primarily curiosity based and in such interactions a large number of intangible contributions arise that cannot be separately attributed. In the process of this research foundational work was required which is published in a companion paper.

\section{ADDITIONAL INFORMATION}

Supplementary information accompanies the paper on the npj Climate and Atmospheric Science website (https://doi.org/10.1038/s41612-018-0034-8).

Competing interests: The authors declare no competing interests.

Publisher's note: Springer Nature remains neutral with regard to jurisdictional claims in published maps and institutional affiliations.

\section{REFERENCES}

1. WHO. Ambient (outdoor) air quality and health. http://www.who.int/mediacentre/ factsheets/fs313/en/ (2015).

2. WHO. Air quality guidelines for particulate matter, ozone, nitrogen dioxide and sulfur dioxide: Summary of risk assessment (WHO, Geneva, 2015).

3. United States Environmental Protection Agency, Air Quality Index: A guide to your health EPA-456/F-14-002 (USEPA, Wash. D.C., 2015).

4. National Academy of Sciences, Rethinking the Ozone Problem in Urban and Regional Air Pollution (NRC, Washington D.C., 1991).

5. Seinfeld J. H. Chemistry and physics of air pollution (J. Wiley, N.Y., 1986)

6. Seinfeld J. H. \& Pandis S. N. Atmospheric chemistry and physics (J. Wiley, N.Y., 1998).

7. Khalil M. A. K. Steady states and transport processes in urban Saudi Arabia NPJ: Climate and Atmospheric Science, https://doi.org/10.1038/s41612-018-0035-7 (2018).

8. Butenhoff, C. L. et al. Evaluation of ozone, nitrogen dioxide and carbon monoxide at nine sites in Saudi Arabia during 2007. J. Air Waste Manage. Assoc 65, 871-886 (2015).

9. Khalil M.A.K. et al. Air quality at Yanbu, Saudi Arabia, J. Air Waste Manage. Assoc. https://doi.org/10.1080/10962247.2015.1129999 (2015).

10. WeatherSpark. Beautiful weather graphs and maps. https://weatherspark.com/. The data are no longer being supplied: https://www.facebook.com/ WeatherSpark-270402379655175/ (2015)

11. Alghamdi M. A. et al. Temporal variations of $\mathrm{O}_{3}$ and NOx in the urban background atmosphere of the coastal city Jeddah, Saudi Arabia. Atmos. Environ. 94, 205-214 (2014).

12. Al-Jeelani, H. A. Air quality assessment at Al-Taneem area in the Holy Makkah City, Saudi Arabia. Environ. Monit. Assess. 156, 211-222 (2009).

13. Platt, U., LeBras, G., Poulet, G., Burrows, J. P. \& Moortgat, G. Peroxy radicals from night-time reaction of $\mathrm{NO}_{2}$ with organic compounds. Nature 348, 147-149 (1990).

14. Lu Y. \& Khalil M. A. K. Model calculations of night-time atmospheric OH. Tellus 44B, 106-113 (1990)

15. Shirley T. R. et al. Atmospheric oxidation in the Mexico City Metropolitan Area (MCMA) during April 2003. Atmos. Chem. Phys. 6, 2753-2765 (2006) www.atmoschem-phys.net/6/2753/2006/

16. Gaudel, A., Ancellet, G. \& Godin-Beekmann, S. Analysis of 20 years of tropospheric ozone vertical profiles lidar and EEC at Observatoire de Haute Provence (OHP) at 44oN, 6.7oE. Atmos. Environ. 113, 78-89 (2015).

17. VanCuren, R. Transport aloft drives peak ozone in the Mojave Desert. Atmos. Environ. 109, 331-341 (2015).

18. Porter, W. C. et al. Annual and weekly patterns of ozone and particulate matter in Jeddah, Saudi Arabia. J. Air Waste Manage Assoc 64, 817-826 (2014).

19. Hassan I. A., Basahi J. M., Ismail I. M., Habeebullah T. M. Spatial distribution and temporal variation in ambient ozone and its associated NOx in the atmosphere of Jeddah City, Saudi Arabia. Aerosol Air Qual. Res. 13: 1712-1722 (2013).

20. Viviano F. Kingdon on the edge: Saudi Arabia, National Geographic Magazine http://ngm.nationalgeographic.com/features/world/asia/saudi-arabia/saudiarabia-text/ (2003).

21. Madronich, S. Photodissociation in the atmosphere 1. Actinic flux and the effects of ground reflections and clouds. J. Geophys. Res. 92, 9740-9752 (1987).

22. Bey, I. et al. Global modeling of tropospheric chemistry with assimilated meteorology: Model description and evaluation. J. Geophys. Res. 106, 073-23096 (2001).

23. Sun Q., Wang Z., Li Z., Erb A., \& Schaaf C. L. B. Evaluation of the global MODIS 30 arc-second spatially and temporally complete snow-free land surface albedo and reflectance anisotropy dataset. Intl. J. Appl. Earth Obs. Geoinf. 58, 36-49 (2017).

\begin{abstract}
Open Access This article is licensed under a Creative Commons Attribution 4.0 International License, which permits use, sharing, adaptation, distribution and reproduction in any medium or format, as long as you give appropriate credit to the original author(s) and the source, provide a link to the Creative Commons license, and indicate if changes were made. The images or other third party material in this article are included in the article's Creative Commons license, unless indicated otherwise in a credit line to the material. If material is not included in the article's Creative Commons license and your intended use is not permitted by statutory regulation or exceeds the permitted use, you will need to obtain permission directly from the copyright holder. To view a copy of this license, visit http://creativecommons. org/licenses/by/4.0/.
\end{abstract}

(c) The Author(s) 2018 